Asian Spine Journal

Vol. 3, No. 1, pp 39 44, 2009

\title{
Pathophysiology of Degenerative Disc Disease
}

\author{
Yong-Soo Choi \\ Department of Orthopedic Surgery, Kwangju Christian Hospital, Gwangju, Korea
}

\begin{abstract}
The intervertebral disc is characterized by a tension-resisting annulus fibrosus and a compression-resisting nucleus pulposus composed largely of proteoglycan. The most important function of the annulus and nucleus is to provide mechanical stability to the disc. Degenerative disc disease in the lumbar spine is a serious health problem. Although the three joint complex model of the degenerative process is widely accepted, the etiological basis of this degeneration is poorly understood. With the recent progress in molecular biology and modern biological techniques, there has been dramatic improvement in the understanding of aging and degenerative changes of the disc. Knowledge of the pathophysiology of the disc degeneration can help in the appropriate choice of treatment and to develop tissue engineering for biological restoration of degener ated discs.
\end{abstract}

Key Words: Lumbar spine, Degenerative disc, Pathophysiology

\section{Introduction}

Lumbar disc degeneration is the most common cause of low back pain and it is a target of diagnostic and surgical intervention. Although the specific underlying pathology of intervertebral disc degeneration has been approached from a variety of ways, there is no consensus as to what disc degeneration actually is or how it can be distinguished from the physiological process of growth, aging, healing and adaptive remodeling. This paper evaluated the pathophysiology of disc degeneration from a review of the existing literature.

\section{Anatomy and Physiology of the Disc}

An intervertebral disc consists of three components: an inner gelatinous nucleus pulposus, outer annulus fibrosus and cartilage end plates located superiorly and inferiorly. The outer annulus fibrosus, which is abundant in type I collagen, is a circular layer that is resistant to tensile strength because the collagen fibers run oblique between the lamellae of the annulus in alternating directions. The nucleus pulposus consists of a proteoglycan and water gel held together loosely by irregular networks of fine type II collagen and elastin fibers. The major proteoglycan of the nucleus pulposus is aggrecan ${ }^{1}$, which provides the osmotic properties needed to resist compression. The intervertebral disc is one of the largest avascular tissues in the body. Disc tissues derive their nutrition from vessels in the subchondral bone adjacent to the hyaline cartilage of the end plate. Small molecules, such as glucose and oxygen, are carried through the end plate in passive diffusion process ${ }^{2}$. The cells in the disc maintain the biological metabolism of the discs by controlling numerous materials, such as cytokines, enzymes, and growth factors.

Chondrocytes produce proteoglycan and collagen, which is the basic skeletal structure of a disc. A monomer of proteoglycan consists of a protein core linked to extended polysaccharide chains, such as keratan sulfate and chondroitin sulfate. Each monomer is bound to hyaluronic acid by a link protein. Aggrecan is the most common proteoglycan in the disc (Fig. 1), and comprises approximately $70 \%$ of the

Received Jan 15, 2009; 1st revised Mar 30, 2009; accepted Apr 28, 2009 


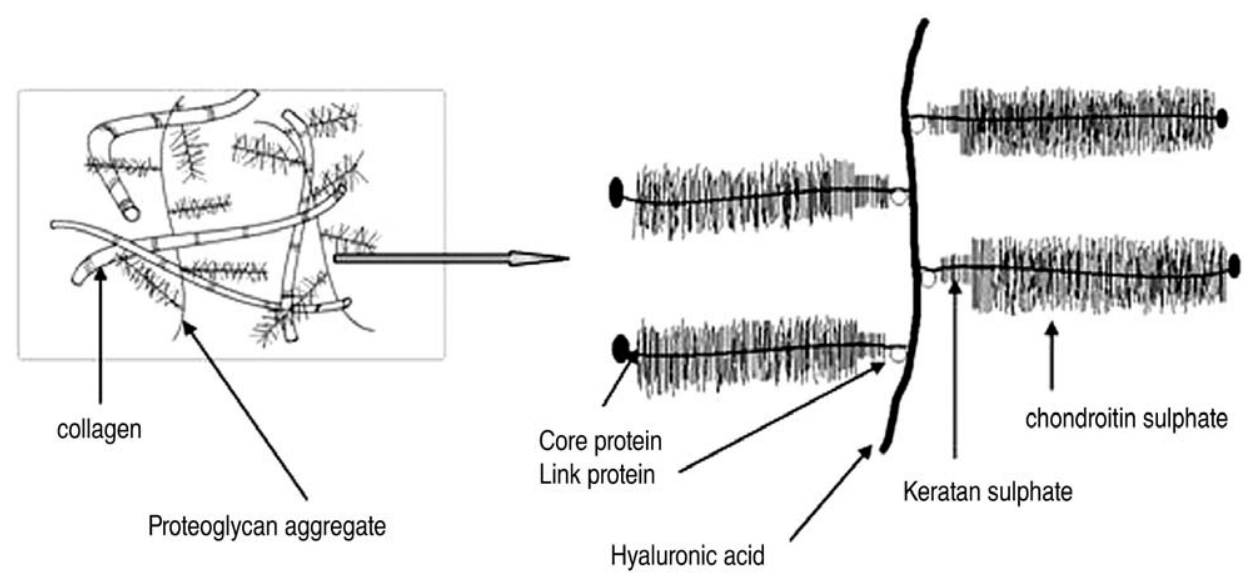

Fig. 1. Illustration of the assemblies of matrix proteins into structures in the intervertebral disc.

nucleus pulposus and $25 \%$ of the annulus fibrosus. A normal disc is responsible for retaining water within the matrix resulting in high viscoelasticity. Aggrecan has high osmotic pressure arising from the water retained within the nucleus pulposus and tends to inflate the collagen framework ${ }^{3}$. As the nucleus pulposus is located between the vertebral end plates and annulus fibrosus, it cannot be expanded but has the potential of expansion, which is known as turgor of the nucleus pulposus. The high concentration of aggrecan in a normal disc enables the tissue to support compressive loads without collapsing and the loads are transferred equally to the annulus fibrosus and vertebral body during flexion and extension movement of the spine ${ }^{4}$.

\section{Healing of an Injured Intervertebral Disc}

Chondrocytes of the intervertebral disc synthesize their matrix and break down the existing matrix by producing and activating degradative enzymes, including matrix metalloproteinases (MMPs), a disintegrin and metalloproteinase $(\text { ADAMS })^{5-7}$. Turnover markers of the matrix and the formation of proteoglycan are maintained at the highest level in adolescence and usually decrease thereafter ${ }^{8}$.

Injured intervertebral discs have a higher concentration of catabolic cytokines, activity of MMPs ${ }^{8,9}$, and formation of scar tissue ${ }^{10}$. If the annulus fibrosus is injured, the nucleus pulposus will escape through the injured annulus fibrosus because it is not fully replaced with chondroid tissue. The healing process of an injured annulus is overtaken by degenerative changes.

\section{Degenerative Change of Intervertevral Disc}

Several factors have been reported to cause disc degeneration. A genetic predisposition to disc degeneration has been proven by studies on twins ${ }^{11-17}$. A polymorphism (5A and $6 \mathrm{~A}$ alleles) commonly occurs in the promoter region of the gene that regulates MMP- 3 production ${ }^{18}$. The $5 \mathrm{~A}$ allele is considered to be a risk factor for the accelerated degenerative changes in the lumbar discs of elderly people but not in the young population ${ }^{19}$. Growth factors, such as transforming growth factor, insulin-like growth factor and basic fibroblast growth factor, stimulate the chondrocytes or fibroblasts to produce more extracellular matrix, and inhibit the production of matrix metalloproteinases ${ }^{20}$. An increase in the level of the basic fibroblast growth factor and transforming growth factor promotes the repair of the degraded matri $^{21,22}$. The intervertebral disc is the largest avascular tissue in the body. The cells in the center of an adult lumbar disc are approximately $8 \mathrm{~mm}$ away from the nearest blood supply ${ }^{23}$. The cells in the outer annulus obtain nutrients from the blood vessels in the soft tissues around its periphery as well as from a sparse penetration of capillaries into its outermost region ${ }^{24}$. The nucleus and cells of the inner annulus depend on a more complicated path extending from the blood vessels of the vertebral body to a capillary network that penetrates the subchondral plate. The nutrients diffuse from these capillaries across the cartilaginous endplate and through the dense disc matrix to the cells ${ }^{25}$. Poor transport of nutrients into the disc is considered to be a cause of disc degeneration ${ }^{26}$. Disc degeneration appears to have a relationship with age. Although many studies have been carried 
out to prove these relationships, such as declining nutrition, cell senescence, the accumulation of degraded matrix products and fatigue failure of the nucleus, no distinct cause has been established ${ }^{27}$. The concentration of cells in the annulus decreases with age $\mathrm{e}^{10,28,29}$. The cells from the disc are subject to senescence and lose their ability to proliferate ${ }^{30,31}$. Decreased anabolism or increased catabolism of senescent cells may promote degeneration ${ }^{31-33)}$ Although all discs are the same age, discs at the lower lumbar segments are more vulnerable to degenerative changes than the upper lumbar segments ${ }^{34}$. This suggests that mechanical loading is a causative factor, rather than simple aging.

The decrease in the number and activity of disc cells depends on the mechanical loading, nutrient transport, life style, genetic factors and growth factors (Fig. 2). Those factors alter the aggrecan and collagen metabolism. As aging progresses, the strongly hydrophilic chondroitin-4-sulfate (chondroitin sulfate A) and chondroitin-6-sulfate (chon-

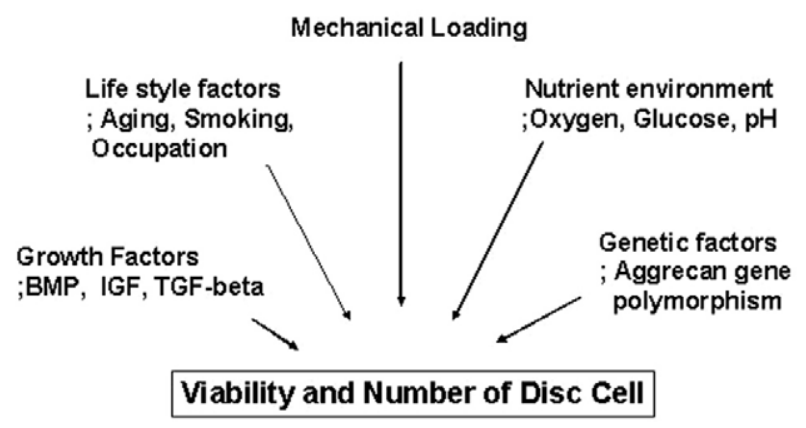

Fig. 2. Factors influencing disc cell turnover. droitin sulfate C) concentrations are decreased, and the keratan sulfate to chondroitin sulfate ratio increases. Keratan sulfate has a smaller hydrophilic potential and less tendency to form stable aggregates with hyaluronic acid. The viscosity and hydrophilicity of the nucleus pulposus decreases as aggrecan is fragmented and its molecular weight and number are decreased. More degenerative changes to the intervertebral disc are promoted as the hydrostatic pressure of the nucleus pulposus and supply of nutrients by diffusion are decreased. If the water content of the extracellular matrix is decreased, there will be a decrease in the height of the intervertebral disc as well as the resistance of the disc to an axial load ${ }^{35}$. Tearing of the annulus clefts can occur easily as the axial load is transferred directly to the annular fibrosus.

Loss and fragmentation of aggrecan will occur with the progress of degenerative change due to the decreased number and activity of disc cells. The distribution and type of collagen in the nucleus will change, e.g. type 1 collagen, which will result in a failure to form the structural framework of the disc. The loss of aggrecan from a degenerative disc influences the load-bearing pattern of the disc as the osmotic pressure of the disc falls, and the disc is less able to maintain hydration under load. When the load on a normal disc is increased, the amount of aggrecans and its osmotic pressure will sufficient to bear the $\operatorname{load}^{3}$. On the other hand, since degenerative discs fail to bear hydrostatic press and structural framework, the load on the discs will cause a loss of height leading to bulging of the discs. Degenerated discs

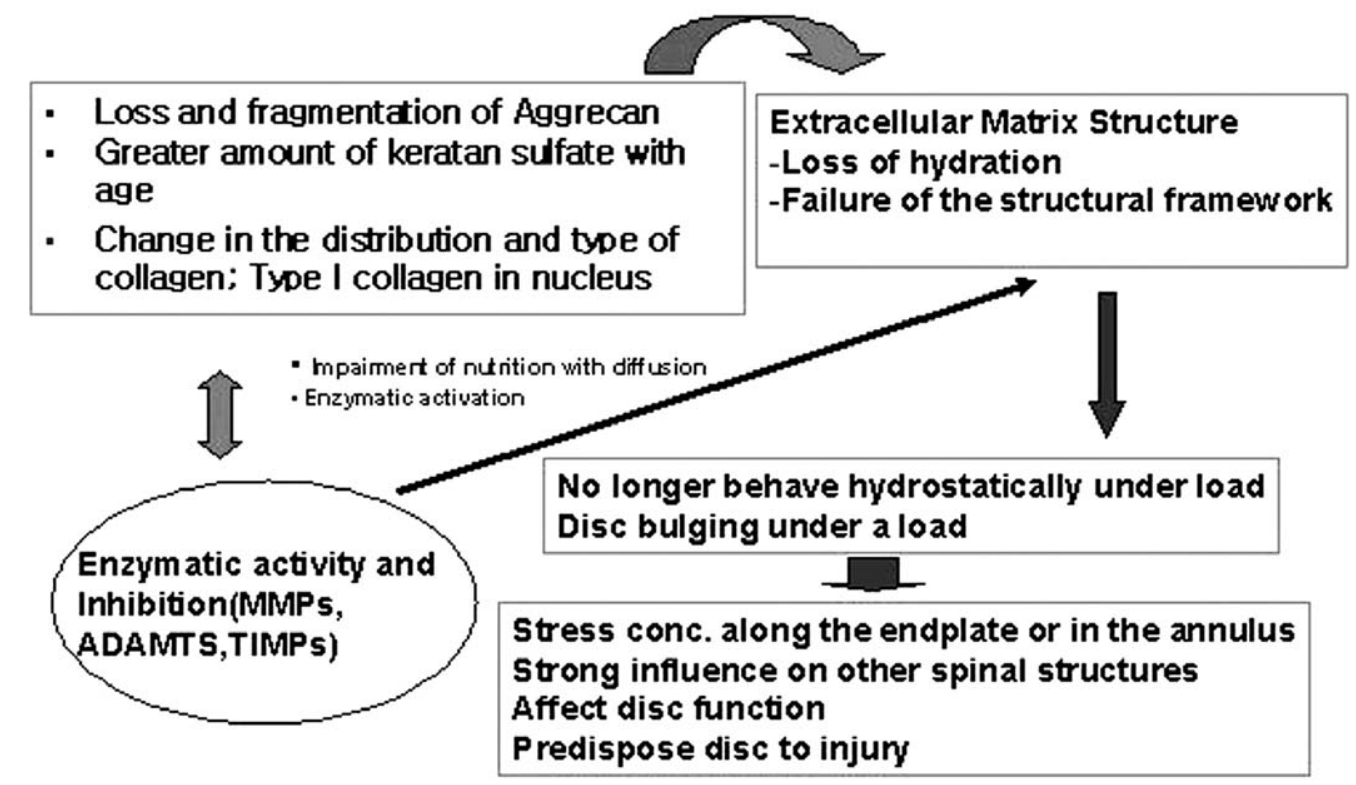

Fig. 3. The spectrum of pathogenesis of the degenerative changes in the intervertebral disc. 
no longer function hydrostatically under load. The stress of the load concentrates along the endplate and the annulus ${ }^{36}$. An annular bulge results from less resistance against tension under load. These changes in a degenerative disc have a strong influence on the other spinal structures and can affect their function, predisposing the disc to injury (Fig. 3).

Yong-Hing and Kirkaldy-Willis ${ }^{37}$ described the intervertebral articulation as a three-joint complex, comprising the disc anteriorly and the two facet joints posteriorly. At the disc, circumferential annular tears progress to radial tears. Herniation can occur when nuclear materials protrude or extrude into the perinural space through radial tears of the annulus. Complete internal disruption of the disc progresses to a subsequent loss of disc height and annular laxity. The loss of disc height alters the facet joint mechanics resulting in the formation of osteophytes at the disc margins. The cascade of degenerative changes at the facet joints resembles those occurring at any synovial joint, which progresses as follows: beginning with synovitis and progressing to articular cartilage destruction, capsular redundancy and joint subluxation. Hypertrophic osteophytes form at the margins of the facet joints and periarticular fibrosis results in stiff facet joints. Coincidentally, a decrease in intervertebral height causes buckling of the ligament flavum and facet overriding. Degenerative changes occur in a parallel manner at all three components, which may cause narrowing of the neuroforaminal and spinal canals.

In addition, the failure of nutritional supply to the disc cells is believed to be another cause of disc degeneration. As aging progresses, the nutritional deficiency of the disc cells is accelerated by smoking, endplate calcification, and the overall nutritional status. The nutritional deficiency and lower oxygen pressure in the discs leads to the accumulation of lactic acid. These changes can affect the ability of disc cells to synthesize and maintain the extracellular matrix of the discs and cause disc degeneration. The degenerated discs cannot respond properly to a normal external load and the risk of internal disruption increases, even by back strain $^{38}$.

In contrast to other musculoskeletal systems, the intervertebral disc exhibits degenerative changes in the late second or early third decade. However, the degenerated disc does not always evoke symptoms. According to Boden's study ${ }^{39}$, there is disc degeneration in at least one lumbar level in $35 \%$ of subjects between twenty and thirty-nine years of age but all subjects sixty to eighty years of age show disc degeneration. It is quite difficult to differentiate the normal aging process from pathological degeneration in patients showing symptoms ${ }^{4}$.

The degenerative changes to the intervertebral disc are a cellular-mediated reaction, which is destroyed during the normal progression and reconstruction of the injured structure of the discs. Although a mechanical load precipitates disc degeneration, the most important causes of degeneration include various processes that impair its healing response. Early degenerative changes to the disc could be defined as biochemical and metabolic changes with aging without any structural failure. On the other hand, degenerative disc disease should be applied to a painful degenerative disc with structural failure, including radial tear of the annulus fibrosus, herniated intervertebral disc, calcification or damage to the end plate, and internal disc disruption ${ }^{40-42}$.

\section{Discogenic Pain}

The nervous system around the disc is affected by disc degeneration, which can stimulate the nociceptors in the anulus fibrosus and cause nociceptive pain, which is referred to as discogenic pain. Substance P, calcitonin generelated peptide, and vasoactive intestinal polypeptide immunoreactive nerve fibers are present in the absolute outer layers of the anulus fibrosus of a normal disc $\mathrm{di}^{43}$. Degenerative changes in the discs, such as loss of the normal structure and a mechanical load, can lead to abnormal motion, which can provoke mechanical stimulation. Mechanical stimuli, which are normally innocuous to disc nociceptors can, in certain circumstances, generate an amplified response termed peripheral sensitisation ${ }^{44}$. The presence of lactic acid leads to a low $\mathrm{pH}$ and stimulates the neurogenic and non-neurogenic pain mediator, provoking pain. In addition, the pathological characteristics of the disc from patients with discogenic pain reveals the formation of zones of vascularized granulation tissue and extensive innervation extending from the outer layer of the anulus fibrosus into the nucleus pulposus along a torn fissure of the annulus. There is abundant infiltration of mast cells in the granulation tissue zones. Mast cells contribute to disc tissue inflammation, neovascularization, fibrosis formation, disc tissue degradation and secrete the nerve growth factor, which might be a signaling substance, such as tumor necrosis factor and interleukins, and play a role in the development of back pain. For example, phospholipase A2 (PLA2), which is related to the arachidonic acid cascade, is detected 
at high concentrations in a degenerative disc ${ }^{45}$. When PLA2 is released into the disc, it stimulates the nociceptors of the outer third of annulus fibrosus, which release inflammatory materials that trigger pain. Neural tissues exposed to PLA2 exhibit intraneural edema, demyelination and axonal injury.

Discogenic pain arises from not only structural failure of the disc but also from nociceptive neurotransmitters, and neural and vascular ingrowth in the outer annulus fibrosus, even though it has not been clearly verified ${ }^{46}$.

Currently, there is no clear boundary between the aging changes and pathological degeneration of the disc, even though a MRI examination has improved the clinical understanding of degeneration, including annular tears, loss of signal in the nucleus and annulus, and facet joint degeneration. Understanding the pathogenesis of disc degeneration can help select the appropriate treatment strategy and develop tissue engineering for biological restoration of degenerated discs. In the future, an ideal treatment for degenerative disc disease must achieve not only pain relief but also the biological reversal of the degenerative cascade. In addition, it is essential to establish a pain mechanism in degenerative disc disease because structural failure of the disc does not always correspond to pain.

\section{REFERENCES}

1. Borgesen SE, Vang PS: Herniation of the lumbar intervertebral disk in children and adolescents. Acta Orthop Scand 1974; 45: 540-549.

2. Key JA: Intervertebral-disc lesions in children and adolescents. J Bone Joint Surg Am 1950; 32: 97-102.

3. Lowrey JJ: Dislocated lumbar vertebral epiphysis in adolescent children: report of three cases. J Neurosurg 1973; 38: 232-234.

4. Parisini P, Di Silvestre M, Greggi T, Miglietta A, Paderni S: Lumbar disc excision in children and adolescents. Spine (Phila Pa 1976) 2001; 26: 1997-2000.

5. Shillito J Jr: Pediatric lumbar disc surgery: 20 patients under 15 years of age. Surg Neurol 1996; 46: 14-18.

6. Sovio OM, Bell HM, Beauchamp RD, Tredwell SJ: Fracture of the lumbar vertebral apophysis. J Pediatr Orthop 1985; 5: 550-552.

7. Ishihara H, Matsui H, Hirano N, Tsuji H: Lumbar intervertebral disc herniation in children less than 16 years of age: long-term follow-up study of surgically managed cases. Spine (Phila Pa 1976) 1997; 22: 2044-2049.
8. Kirkaldy-Willis WH, Paine KW, Cauchoix J, McIvor

G: Lumbar spinal stenosis. Clin Orthop Relat Res 1974; (99): 30-50.

9. Wahren H: Herniated nucleus pulposus in a child of twelve years. Acta Orthop Scand 1946; 16: 40-42.

10. Epstein JA, Lavine LS: Herniated lumbar intervertebral discs in teen-age children. J Neurosurg 1964; 21: 10701075 .

11. Varlotta GP, Brown MD, Kelsey JL, Golden AL: Familial predisposition for herniation of a lumbar disc in patients who are less than twenty-one years old. J Bone Joint Surg Am 1991; 73: 124-128.

12. Zhu Q, Gu R, Yang X, et al: Adolescent lumbar disc herniation and hamstring tightness: review of 16 cases. Spine (Phila Pa 1976) 2006; 31: 1810-1814.

13. Zamani MH, MacEwen GD: Herniation of the lumbar disc in children and adolescents. J Pediatr Orthop 1982; 2: 528-533.

14. Kurth AA, Rau S, Wang C, Schmitt E: Treatment of lumbar disc herniation in the second decade of life. Eur Spine J 1996; 5: 220-224.

15. DeOrio JK, Bianco AJ Jr: Lumbar disc excision in children and adolescents. J Bone Joint Surg Am 1982; 64: 991996.

16. Grobler LJ, Simmons EH, Barrington TW: Intervertebral disc herniation in the adolescent. Spine (Phila Pa 1976) 1979; 4: 267-278.

17. Smorgick Y, Floman Y, Millgram MA, et al: Mid- to long-term outcome of disc excision in adolescent disc herniation. Spine J 2006; 6: 380-384.

18. Ye S, Watts GF, Mandalia S, Humphries SE, Henney AM: Preliminary report: genetic variation in the human stromelysin promoter is associated with progression of coronary atherosclerosis. Br Heart J 1995; 73: 209-215.

19. Takahashi M, Haro H, Wakabayashi Y, et al: The association of degeneration of the intervertebral disc with $5 \mathrm{a} / 6 \mathrm{a}$ polymorphism in the promoter of the human matrix metalloproteinase-3 gene. J Bone Joint Surg Br 2001; 83: 491495.

20. Seki S, Kawaguchi Y, Chiba K, et al: A functional SNP in CILP, encoding cartilage intermediate layer protein, is associated with susceptibility to lumbar disc disease. Nat Genet 2005; 37: 607-612.

21. Peng B, Hao J, Hou S, et al: Possible pathogenesis of painful intervertebral disc degeneration. Spine (Phila $\mathrm{Pa}$ 1976) 2006; 31: 560-566.

22. Doita M, Kanatani T, Harada T, Mizuno K: Immunohis- 
tologic study of the ruptured intervertebral disc of the lumbar spine. Spine (Phila Pa 1976) 1996; 21: 235-241.

23. Katz MM, Hargens AR, Garfin SR: Intervertebral disc nutrition: diffusion versus convection. Clin Orthop Relat Res 1986; (210): 243-245.

24. Boos N, Weissbach S, Rohrbach H, et al: Classification of age-related changes in lumbar intervertebral discs: 2002 Volvo Award in basic science. Spine (Phila Pa 1976) 2002; 27: 2631-2644.

25. Roberts S, Urban JP, Evans H, Eisenstein SM: Transport properties of the human cartilage endplate in relation to its composition and calcification. Spine (Phila Pa 1976) 1996; 21: 415-420.

26. Nachemson A, Lewin T, Maroudas A, Freeman MA: In vitro diffusion of dye through the end-plates and the annulus fibrosus of human lumbar inter-vertebral discs. Acta Orthop Scand 1970; 41: 589-607.

27. Buckwalter JA: Aging and degeneration of the human intervertebral disc. Spine (Phila Pa 1976) 1995; 20: $1307-$ 1314.

28. Trout JJ, Buckwalter JA, Moore KC, Landas SK: Ultrastructure of the human intervertebral disc. I: changes in notochordal cells with age. Tissue Cell 1982; 14: 359369.

29. Trout JJ, Buckwalter JA, Moore KC: Ultrastructure of the human intervertebral disc: II. cells of the nucleus pulposus. Anat Rec 1982; 204: 307-314.

30. Gruber HE, Ingram JA, Norton HJ, Hanley EN Jr: Senescence in cells of the aging and degenerating intervertebral disc: immunolocalization of senescence-associated beta-galactosidase in human and sand rat discs. Spine (Phila Pa 1976) 2007; 32: 321-327.

31. Roberts S, Evans EH, Kletsas D, Jaffray DC, Eisenstein SM: Senescence in human intervertebral discs. Eur Spine J 2006; 15 Suppl 3: S312-316.

32. Oshima J, Campisi J: Fundamentals of cell proliferation: control of the cell cycle. J Dairy Sci 1991; 74: 2778-2787.

33. West MD, Pereira-Smith OM, Smith JR: Replicative senescence of human skin fibroblasts correlates with a loss of regulation and overexpression of collagenase activity. Exp Cell Res 1989; 184: 138-147.

34. Miller JA, Schmatz C, Schultz AB: Lumbar disc degeneration: correlation with age, sex, and spine level in 600 autopsy specimens. Spine (Phila Pa 1976) 1988; 13: 173178.
35. Fraser RD, Bleasel JF, Moskowitz RW: Spinal degeneration: pathogenesis and medical management. (in Frymoyer JW, Ducker TB, Hadler NM, et al. eds. The adult spine: principles and practice, 2nd ed. Philadelphia, LippincottRaven, 1997)

36. Adams MA, McNally DS, Dolan P: 'Stress'distributions inside intervertebral discs: the effects of age and degeneration. J Bone Joint Surg Br 1996; 78: 965-972.

37. Yong-Hing K, Kirkaldy-Willis WH: The pathophysiology of degenerative disease of the lumbar spine. Orthop Clin North Am 1983; 14: 491-504.

38. Horner HA, Urban JP: 2001 Volvo Award Winner in Basic Science Studies: effect of nutrient supply on the viability of cells from the nucleus pulposus of the intervertebral disc. Spine (Phila Pa 1976) 2001; 26: 2543-2549.

39. Boden SD, Davis DO, Dina TS, Patronas NJ, Wiesel SW: Abnormal magnetic-resonance scans of the lumbar spine in asymptomatic subjects: a prospective investigation. J Bone Joint Surg Am 1990; 72: 403-408.

40. Fardon DF: Nomenclature and classification of lumbar disc pathology. Spine (Phila Pa 1976) 2001; 26: 461-462.

41. Solovieva S, Lohiniva J, Leino-Arjas P, et al: COL9A3 gene polymorphism and obesity in intervertebral disc degeneration of the lumbar spine: evidence of gene-environment interaction. Spine (Phila Pa 1976) 2002; 27: 26912696.

42. Videman T, Battie MC, Gill K, et al: Magnetic resonance imaging findings and their relationships in the thoracic and lumbar spine: insights into the etiopathogenesis of spinal degeneration. Spine (Phila Pa 1976) 1995; 20: 928-935.

43. Konttinen YT, Gronblad M, Antti-Poika I, et al: Neuroimmunohistochemical analysis of peridiscal nociceptive neural elements. Spine (Phila Pa 1976) 1990; 15: 383-386.

44. Brisby H: Pathology and possible mechanisms of nervous system response to disc degeneration. J Bone Joint Surg Am 2006; 88 Suppl 2: 68-71.

45. Franson RC, Saal JS, Saal JA: Human disc phospholipase A2 is inflammatory. Spine (Phila Pa 1976) 1992; 17 Suppl 6: S129- S132.

46. Buckwalter JA, Boden SD, Erye DR, et al: Intervertebral disc aging, degeneration, and, herniation. (in Buckwalter JA, Einhorn TA, Simon SR, eds. Orthopaedic basic science, 2nd ed. Rosement, American Academy of Orthopaedic Surgeons: 557-566, 2000). 